\title{
A INFLUÊNCIA DAS IDEOLOGIAS PARTIDÁRIAS NOS GASTOS PÚBLICOS EM ASSISTÊNCIA SOCIAL NAS CAPITAIS BRASILEIRAS
}

\section{THE INFLUENCE OF PARTY IDEOLOGIES ON PUBLIC SPENDING IN SOCIAL ASSISTANCE IN BRAZILIAN CAPITALS}

\section{LA INFLUENCIA DE LAS IDEOLOGÍAS DE LOS PARTIDOS EN EL GASTO PÚBLICO EN ASISTENCIA SOCIAL EN CAPITALES BRASILENAS}

\begin{abstract}
RESUMO
É notório que os termos "esquerda" e "direita" continuam sendo utilizados, mesmo que às vezes sem o devido rigor. Levando isso em consideração vem se estudando o quanto a ideologia impacta no comportamento dos atores políticos. Diante desse cenário, 0 presente trabalho explora a acepção dos termos e busca verificar em que medida há relação entre ideologia e investimentos públicos, mais especificamente direcionados à assistência social nas capitais brasileiras entre 2013 e 2016. Os investimentos foram acessados no Sistema de Informações Contábeis e Fiscais do Setor Público Brasileiro (Siconfi) e foi levado em consideração tanto o partido do prefeito quanto do vice-prefeito para construir o que se chamou de enquadramento ideológico (esquerda-esquerda, esquerda-direita, direita-esquerda e direita-direita). Foi acessado também o IDHM dos municípios, últimos dados disponíveis. Para análise, a pesquisa utilizou estatística descritiva e multivariada, considerando os dados por meio de três técnicas: box-plot, correlação de Spearman e regressão linear múltipla. Os resultados encontrados possibilitaram verificar que o impacto da ideologia política nos gastos sociais, contrariando o que se esperaria teoricamente, é nulo. Por sua vez, encontrou-se uma relação significativa entre IDHM e investimentos em assistência social. A variação de 1 ponto percentual em IDHM provoca uma variação positiva de 0,032 pontos percentuais no investimento (arrecadação/despesa).
\end{abstract}

PALAVRAS-CHAVE: ideologias partidárias, comportamento politico, capitais brasileiras, investimentos públicos, assistência social.

\section{Fernando Scheeffer ${ }^{1}$}

fernando.scheeffer@udesc.br

ORCID: https://orcid.org/0000-0003-3225-6011

Dinorá Baldo de Faveri ${ }^{1}$

dinora.faveri@udesc.br

ORCID: https://orcid.org/0000-0002-6118-9578

Eliel Santos da Silva Junior ${ }^{1}$

elielespartano@hotmail.com

ORCID: https://orcid.org/0000-0003-4012-1061

1. Universidade do Estado de Santa Catarina, Departamento de Ciências Contábeis, Ibirama, SC, Brasil.

Submetido 05.03.2019. Aprovado 06.02.2020

Avaliado pelo processo de double blind review.

DOI: http://dx.doi.org/10.12660/cgpc.v25n80.78480

Esta obra está submetida a uma licença Creative Commons 
Fernando Scheeffer - Dinorá Baldo de Faveri - Eliel Santos da Silva Junior

\section{ABSTRACT}

It is notorious that the terms left and right continue to be used, even if sometimes without due rigor. Taking this into consideration has been studying how much ideology impacts on the behavior of political actors. Given this scenario, the present work explores the meaning of the terms and seeks to verify to what extent there is a relationship between ideology and public investments, more specifically directed to social assistance in Brazilian capitals between 2013 and 2016. Investments were accessed in the Accounting Information System and (SICONFI) and the party of the mayor and deputy mayor was taken into account to construct what was called the ideological framework (left-left, left-right, right- left and right-right). The IDHM of the municipalities was also accessed, last available data. For the analysis, we used descriptive and multivariate statistics, analyzing the data using three techniques: box-plot, Spearman correlation and multiple linear regression. The results found make it possible to verify that the impact of political ideology on social expenditures, contrary to what would theoretically be expected, is zero. In turn, a significant relationship was found between IDHM and investments in social assistance. The change of 1 percentage point in HDI causes a positive variation of 0.032 percentage points in the investment (collection / expenditure).

KEYWORDS: party ideologies, political behavior, brazilian capitals, public investments, social assistance.

\section{RESUMEN}

Es notorio que los términos izquierda y derecha continúan siendo utilizados, aunque a veces sin el debido rigor. Tomando esto en consideración se viene estudiando cuánto la ideolog ía impacta en el comportamiento de los actores políticos. En este contexto, el presente trabajo explora la acepción de los términos y busca verificar en qué medida hay relación entre ideolog ía e inversiones públicas, más específicamente dirigidas a la asistencia social en las capitales brasileñas entre 2013 y 2016. Las inversiones fueron accedidas en el Sistema de Informaciones Contables y (SICONFI) y fue tomado en consideración tanto el partido del prefecto y el vice-alcalde para construir lo que se llamó de encuadramiento ideológico (izquierda-izquierda, izquierda-derecha, derecha- izquierda y derecha-derecha). Se accede también al IDHM de los municipios, últimos datos disponibles. Para análisis la investigación se utilizó de estadística descriptiva y multivaria, analizando los datos por medio de tres técnicas: box- plot, correlación de Spearman y regresión lineal múltiple. Los resultados encontrados posibilitar verificar que el impacto de la ideología política en los gastos sociales, contrariando lo que se esperaba teóricamente, es nulo. A su vez se encontró una relación significativa entre IDHM é inversiones en asistencia social. La variación de 1 punto porcentual en IDHM provoca una variación positiva de 0,032 puntos porcentuales en la inversión (recaudación / gasto).

PALAVRAS CLABE: ideologías de partido, comportamiento político, capitales brasileños, inversiones públicas, asistencia social.

\section{INTRODUÇÃO}

Recentemente, sobretudo na ciência política, passa a ser foco de interesse a verificação em que grau as supostas diferenças ideológicas entre os partidos acarretam diferentes comportamentos dos atores políticos. Parte da literatura sugere que as questões ideológicas pouco explicam o comportamento dos atores políticos, hoje, ao constatar a presença de outras variáveis mais importantes (Mainwaring, 1993; Zucco JR., 2009; Lucas \& Samuels, 2011). Por outro lado, outra gama de autores, com nuances e metodologias distintas, defende que os atores políticos ainda pautam suas ações nos conteúdos programáticos e nas ideologias de seus respectivos partidos (Kinzo 1993; Leoni, 2002; Scheeffer, 2018).

Segundo Carvalho (2008), as primeiras manifestações da assistência social no Brasil foram relacionadas diretamente a um estado de caridade, uma solidariedade "religiosa" que estaria sendo submetida como auxílio aos pobres, incapazes e doentes, sendo que até esse momento a pobreza não era tratada como uma questão social. Com as mudanças significativas após a Constituição de 1988, a seguridade social ganhou força (saúde, assistência social e previdência social) , acabando por tornar-se uma política 


\section{A INFLUÊNCIA DAS IDEOLOGIAS PARTIDÁRIAS NOS GASTOS PÚBLICOS EM ASSISTÊNCIA SOCIAL NAS CAPITAIS BRASILEIRAS}

pública que garante ao cidadão direitos e traz responsabilidade e dever para o Estado (Santana, Silva, \& Silva, 2013). A partir da consideração da assistência social como direito, o Estado passou a ter responsabilidade perante as necessidades da população. Mesmo com todos os avanços institucionais, o tema da pobreza demonstra-se complexo e tomado por diferentes concepções e abordagens. Dependendo da compreensão que se tem, é possível conceber políticas públicas que busquem trazer soluções eficazes para o problema ou ainda ignorá-lo se concebido como natural. Em se tratando de assistência social, a concepção de pobreza é fundamental visto que implica viabilizar ou não instrumentos de superação. Além disso, os instrumentos utilizados podem ser concebidos no campo do "direito" ou do "favor." Partindo da premissa de que diferentes concepções político-ideológicas deveriam acarretar diferentes posicionamentos dos atores políticos, emerge a pergunta de partida do presente estudo: qual o impacto das ideologias políticas nos gastos públicos em assistência social nas capitais brasileiras? Para dar conta desta resposta, buscou-se analisar os gastos em assistência social nessas cidades no período de 2013 a 2016. De forma acessória, pretendeu-se explorar o significado dos termos esquerda e direita, assim como verificar as diferentes concepções a respeito da pobreza. As várias divergências em relação a essa temática deixam clara sua complexidade e sugerem ser este um campo promissor de estudo.

Poucos são os estudos que se assemelham ao que está sendo feito aqui. O mais próximo é o de Rodrigues (2010), que analisou os investimentos em Santa Catarina e relacionou-os com as matrizes ideológicas de cada partido. $O$ estudo foi realizado com as maiores cidades do Estado durante os anos de 2005-2008 e levando em consideração várias áreas.

Lucas \& Samuels (2011) sugerem que a discussão a respeito da situação dos partidos brasileiros e do sistema partidário é muito parecida com um hipotético debate sobre a forma de uma nuvem no céu, em que cada um vê algo diferente e considera ridícula a visão do outro. Há muita controvérsia a respeito do peso da ideologia em tempos atuais. Diante disso, parece ser relevante analisar o peso que eventualmente ainda têm as ideologias no Executivo municipal.

Para dar conta do objetivo proposto, o artigo inicia com uma discussão a respeito do significado de esquerda e direita, assim como os supostos desdobramentos em relação à assistência social. Feito isso parte-se para procedimentos metodológicos, análise e discussão dos resultados e considerações finais.

\section{ESQUERDA, DIREITA E ASSISTÊNCIA SOCIAL}

A origem dos termos esquerda e direita remonta à Revolução Francesa (1789) quando se iniciaram os trabalhos para a elaboração da primeira Constituição francesa. Os representantes políticos posicionaram-se em lugares diferentes do plenário. À esquerda, sentaram-se delegados identificados com o igualitarismo e que almejavam uma reforma social ampla. À direita, um grupo identificado com a aristocracia e que buscava o status quo (Tarouco \& Madeira, 2013). Assim, essas diferenças espaciais passaram a denotar perfis ideológicos distintos. 
Embora existam autores que defendam que os termos têm o mesmo sentido que tinham na Revolução Francesa ou que não há mais sentido a utilização dessa nomenclatura sobretudo com a derrocada do "socialismo real," a tese que vigora é a de que é necessário atualizar seus significados. $O$ principal representante desta corrente majoritária é Bobbio (1995). Segundo ele, a ideia de igualdade (que para a esquerda deve ser priorizada), em detrimento da liberdade (que para a direita deve ser conservada, mantendo-se as desigualdades entre os homens, tidas como naturais) resume hoje em grande parte projetos distintos e diferenças prático-teóricas entre grupos políticos e pessoas.

O fato é que recentemente a dimensão "mais" ou "menos" Estado tem balizado grande parte do debate político e, por isso, estratégias do tipo social-democratas e neoliberais acabam por dar conta, em boa medida, dos principais projetos políticos defendidos em tempos atuais e endo saídas para a "nova direita" e a "nova esquerda". Pode-se falar em "nova esquerda" e "nova direita", visto que a esquerda adere à social-democracia no lugar do socialismo e a direita ao neoliberalismo, diferente do liberalismo clássico, sobretudo por dar-se em um outro momento histórico.

O neoliberalismo surge depois da Segunda Guerra Mundial, enquanto crítica ao Estado de bem-estar social e à crise fiscal de países que se propunham a oferecer "tudo" a "todos" (Anderson, 1995). Para Moraes (2002), as narrativas neoliberais pretenderam, e em certa medida conseguiram, oferecer explicação palatável para os problemas derivados das políticas sociais ou do
Estado de Bem-Estar Social. Três argumentos são centrais:

- os custos crescentes (e tendencialmente insuportáveis) das políticas sociais e seu impacto sobre os fundos públicos (inflação, endividamento);

- os efeitos deletérios dessas políticas sobre valores, comportamento de indivíduos, grupos sociais e empresas;

- os resultados desastrosos, sobre o processo decisório e sobre as instituições democráticas, da maquinaria política exigida pela implementação desses programas (Moraes, 2002, p. 2).

Em se tratando de social-democracia, Giddens (2000) deixa claro que tem como objetivo "humanizar" o capitalismo, crendo que uma intervenção do Estado daria conta da desigualdade de oportunidades e possibilitaria chances iguais a todos. Segundo ele a social-democracia consistiria, então, em um caminho distinto do capitalismo de mercado americano e do socialismo soviético. A ideologia vê o mercado como um gerador de efeitos perversos, algo que os próprios socialistas já haviam diagnosticado. No entanto, acredita ser possível amenizá-los ou até extingui-los, por meio da intervenção do Estado no mercado. Para a social-democracia clássica, a participação do governo na vida dos indivíduos é algo necessário e invejável. Benefícios estatais são essenciais para o auxílio aos que não conseguiriam, por si só, defender-se.

"Como Marx, Keynes, encarava o capitalismo como dotado de qualidades irracionais, mas acreditava que seria possível controlá-las para salvar o capitalismo de si mesmo" (Giddens, 2000, p. 19). Aggio (2013) apresenta al- 


\section{A INFLUÊNCIA DAS IDEOLOGIAS PARTIDÁRIAS NOS GASTOS PÚBLICOS EM ASSISTÊNCIA SOCIAL NAS CAPITAIS BRASILEIRAS}

guns valores que permanecem como eixos da identidade política e cultural da esquerda hoje, o que se encaixa perfeitamente no conjunto de princípios social-democratas:

- a defesa do bem-estar social ao invés do bem-estar individual;

- a valorização das responsabilidades coletivas;

- a extensão da igualdade de oportunidades para todos;

- a vigência de um Estado forte que seja capaz de corrigir as injustiças sociais por meio de uma ação distributivista da riqueza material produzida pela sociedade;

- a perspectiva de uma mudança das estruturas de poder por meio da democratização e da participação política (p. 102).

No quadro 1, é apresentado o posicionamento político da esquerda e direita frente a diferentes questões da sociedade, que explicam comportamento, pensamentos e crenças ligadas a essas distinções clássicas.

Quadro 1. Divergências em relação a temas ligados às ideologias clássicas

\begin{tabular}{|l|l|}
\hline Esquerda & Direita \\
\hline $\begin{array}{l}\text { A intervenção econômica deve dar-se } \\
\text { sempre que se julgar necessário }\end{array}$ & $\begin{array}{l}\text { O Estado deve abster-se de questões econômi- } \\
\text { cas, já que o mercado se autorregula, como se } \\
\text { houvesse uma "mão invisível" orientando esse } \\
\text { processo. }\end{array}$ \\
\hline $\begin{array}{l}\text { A pobreza dá-se, sobretudo, por desigual- } \\
\text { dade de oportunidades. Enquanto proble- } \\
\text { ma social, pode ser enfrentada via progra- } \\
\text { mas sociais ou superação da ordem, no } \\
\text { caso de uma esquerda mais radical. }\end{array}$ & $\begin{array}{l}\text { A pobreza, quando atacada, deve dar-se de } \\
\text { forma focalizada e limitada. Auxílios "exagera- } \\
\text { dos" podem levar à acomodação e ao declínio } \\
\text { da "ética do trabalho". }\end{array}$ \\
\hline $\begin{array}{l}\text { A criminalidade pode ser explicada, es- } \\
\text { sencialmente, pela inserção em um con- } \\
\text { texto social que oferece desigualdade de } \\
\text { oportunidades. }\end{array}$ & $\begin{array}{l}\text { A criminalidade, em grande parte, é responsa- } \\
\text { bilidade dos indivíduos. }\end{array}$ \\
\hline $\begin{array}{l}\text { A carga tributária deve ser extensiva para } \\
\text { financiar o Estado e oferecer serviços de } \\
\text { qualidade para os que precisarem }\end{array}$ & $\begin{array}{l}\text { Os tributos são maléficos, pois sobrecarregam } \\
\text { as empresas e desfavorecem o crescimento } \\
\text { econômico. }\end{array}$ \\
\hline $\begin{array}{l}\text { Defesa de uma ampla legislação traba- } \\
\text { lhista que normatize o mundo do trabalho. }\end{array}$ & $\begin{array}{l}\text { O mercado de trabalho deve ser desregulado, } \\
\text { visto que o mercado autorregula as relações de } \\
\text { trabalho. }\end{array}$ \\
\hline $\begin{array}{l}\text { Os serviços, sobretudo aqueles estratégi- } \\
\text { cos, devem ser oferecidos pelo Estado. }\end{array}$ & $\begin{array}{l}\text { Buscando diminuir o tamanho do Estado, uma } \\
\text { boa estratégia é passar para a iniciativa privada } \\
\text { serviços que são estatais - privatização. }\end{array}$ \\
\hline
\end{tabular}

Fonte: Scheeffer (2018). 
Para Giddens (2000), a direita e a esquerda ainda representam forças distintas e divergentes quanto ao futuro do welfare state. Em síntese, em defesa da justiça social, os social-democratas exigem um Estado interventor, enquanto os neoliberais, acreditando nas benesses do mercado, defendem um Estado mínimo. Vale destacar que, além da discussão clássica mais ou menos Estado, Inglehart (1977) já previa uma mudança após o século XX no debate político e ideológico, trazendo agora questões relacionadas ao meio ambiente, livre expressão e qualidade de vida no sentido mais amplo. Heywood (2010) afirma que as novas ideologias trazem questões como gênero, etnia e cultura.

Muitas são as concepções a respeito da pobreza e do papel da assistência social. É visível o fato de que na visão (neo)liberal a pobreza é bastante atrelada a uma questão pessoal, a uma questão de escolha. De acordo com Scheeffer, (2013) nessa visão o mercado é o espaço para que os problemas sociais sejam resolvidos. Para Oliveira (2003), sendo o mercado considerado o lugar mais correto para alocação de recursos, o Estado pode diminuir sua influência na sociedade, bem como ter menos funções. No que tange à área social, o autor afirma que o Estado deve se ater a programas de assistência quando necessário e de forma complementar à filantropia privada. A pobreza na visão neoliberal é explicada por Galbraith, citado por Garcia (2005), como a falta de aproveitamento do livre mercado e da livre concorrência. Para o autor, o indivíduo mantém-se na situação de pobreza principalmente pelo excesso de acomodação e pela falta de esforço. Segundo o autor, existem duas grandes linhas de ataque à pobreza: uma é combater a acomodação; a outra é facilitar esse escape por meio de políticas que reforcem essa iniciativa.

Por uma visão social-democrata, a pobreza é tratada de uma forma diferente do neoliberalismo. De acordo com Giddens (2000), o mercado é um dos principais geradores de problemas sociais, cabendo ao Estado intervir no mercado quando necessário. De acordo com Setembrini (1997), faz parte dos princípios da social-democracia que o Estado deve prover uma renda mínima, saúde, habitação, educação e alimentação, não como caridade e sim como um direito do cidadão.

Diante do exposto, percebe-se que as distinções entre social-democratas e neoliberais sintetizam as divergências político-ideológicas recentes. Posto isso, fica a dúvida se essas diferentes concepções a respeito do papel do Estado no combate à pobreza refletem diferentes posicionamentos dos atores políticos.

\section{AS IDEOLOGIAS PARTIDÁRIAS E A CLAS- SIFICAÇÃO DOS PARTIDOS BRASILEI- ROS}

Para Heywood (2010), as ideologias são descritivas pois, em última instância, fornecem a indivíduos e grupos um mapa conceitual de como a sociedade funciona e, de forma mais abrangente, uma visão geral de mundo. As ideologias políticas têm a capacidade de inspirar e guiar a ação política. Questão-chave nessa discussão é qual a validade da ideologia em se tratando de partidos políticos, isto é, se é esta hoje uma variável relevante e em que medida os partidos podem ser classificados em esquerda e direita. 


\section{A INFLUÊNCIA DAS IDEOLOGIAS PARTIDÁRIAS NOS GASTOS PÚBLICOS EM ASSISTÊNCIA SOCIAL NAS CAPITAIS BRASILEIRAS}

Budge Budge, I., Klingemann, H-D., Volkens, A., Bara, J., \& Tanenbaum, E. (2001) buscam, dentre outras questões, responder às seguintes perguntas: existe um declínio do poder explicativo das categorias esquerda e direita? Presenciamos o fim das ideologias? Analisando 24 países da OCDE em duas ondas distintas (1945-1998 e 1990-2003), os autores localizaram as posições políticas dos partidos a partir da análise de conteúdo dos manifestos partidários e buscaram medir suas posições e ainda as mudanças entre uma eleição e outra. Segundo eles, essa dimensão permite verificar tendências e na maioria dos países analisados é possível mapear seus movimentos de forma bastante razoável.

Klingemann, H-D., Volkens, A., Bara, J., Tanenbaum, E., \& McDonald, M. (2006), de forma mais específica, afirmam que em grande parte da Europa existem diferenças significativas entre os partidos políticos no que diz respeito a preocupações típicas da esquerda ou direita. Por meio de sete funções discriminantes, alegam que estas podem dar uma boa ideia das clivagens que moldam a política europeia. Colocadas em ordem decrescente de importância, a função 1 é aquela relacionada à dimensão esquerda e direita, o que denota a preeminência de tal divisão na política partidária dos países em questão.

Dalton \& McAllister (2014) também ressaltam o peso da ideologia ao buscar analisar o quanto em eleições sucessivas há uma continuidade ideológica por parte dos partidos. Utilizando-se dos dados do projeto Comparative Study of Electoral Syste$m s$ (CSES) e de forma complementar do
Chapel Hill Expert Survey (CHES), ambos voltados para as democracias industriais avançadas, constatam que $90 \%$ do posicionamento partidário é previsível, sabendo sua posição na última eleição. Dez por cento da variância pode ser explicada por outros fatores. De forma geral, a maioria dos partidos apresenta perfis ideológicos semeIhantes em todas as eleições. Diferentemente do que se possa supor, há estabilidade ao longo do tempo nas posições esquerda e direita. Vale a ressalva de que as ações de cunho ideológico estão mais associadas aos partidos de extrema esquerda ou direita. Partidos de centro estariam mais propensos a mudar suas estratégias em busca de voto.

Em se tratando do caso brasileiro, Roma (2006), pautando-se em pesquisas de opinião aplicadas aos parlamentares, defende que, embora grande parte da literatura destaque que a disciplina partidária pode ser explicada pela distribuição de recursos orçamentários pelo Executivo, os deputados partilham o ideário do seu partido de filiação e, por esse motivo, demonstram-se coesos. A discordância entre as legendas permite posicioná-los ideologicamente e o parlamentar em geral escolhe seu partido levando em conta a afinidade de crenças.

Scheeffer (2018a) propôs-se a verificar o peso da ideologia no comportamento parlamentar em tempos atuais a partir da análise de um conjunto de votações nominais ocorridas durante o governo Dilma Roussef na Câmara dos Deputados. Analisados temas substantivos do ponto de vista político- ideológico, os partidos em sua maioria posicionam-se de forma coerente com 0 que é esperado. A exceção são os casos em que estão em jogo recursos financeiros, seja 
onerando significativamente ou então gerando receita vultosa ao Executivo federal.

Apresentados alguns estudos que destacam a ainda validade da ideologia partidária em tempos atuais, o próximo passo é discutir minimamente a classificação dos partidos brasileiros. Dalton e McAllister (2014) enfocam a classificação dos partidos expondo que são inúmeros os estudos empíricos utilizando métodos variados para estimar as posições dos partidos em uma escala Esquerda-Direita (E-D). Os métodos mais comuns são os estudos dos manifestos e programas partidários; a avaliação feita por especialistas; a autolocalização no espectro político das elites políticas; bem como a percepção dos cidadãos em relação à localização na escala. Se atendo ao caso brasileiro, Tarouco e Madeira (2013) corroboram afirmando que são muitos os métodos para localizar os partidos no eixo E-D e acrescentam a atuação parlamentar como método relevante.

Zucco Jr. (2011) buscou atualizar o posicionamento ideológico dos principais partidos brasileiros pós-Constituinte. Por meio da Pesquisa Legislativa Brasileira (PLB 2009) e utilizando-se de dados de parlamentares que responderam a mais de uma edição da pesquisa, afirma que o PSOL é o partido mais à esquerda do espectro ideológico brasileiro. Pela primeira vez em 20 anos, 0 DEM/PFL aparece à direita do PP (e seus antecessores), muito provavelmente pela diluição ideológica do PP em função da aliança com o governo Lula. O PPS continua a caminhada para a direita, estando claramente à direita do PSB e do PDT. Por fim, o PSDB continua em uma posição estatisticamente indistinguível à do PMDB (hoje, MDB).
Melo \& Câmara (2012) rejeitam a tese de que o sistema partidário brasileiro encontra-se hoje incoerente, ou ao menos, mais incoerente do que antes, inclusive discordando de que teríamos hoje o "PT contra o resto" (Lucas \& Samuels, 2011). Se é justificável a premissa de que o PT seria de certa forma distinto dos demais partidos brasileiros, para eles teríamos três grandes blocos e não dois. Haveria a existência de um bloco de partidos posicionado entre os dois polos (PMDB, PP, PTB, PR).

A análise de surveys realizados na Câmara dos Deputados corrobora essa afirmação. Teríamos uma clara distinção ideológica entre PT e PSDB, sobretudo no que diz respeito ao papel do Estado na economia, política externa e nas opiniões sobre questões como união de pessoas do mesmo sexo e aborto. Por sua vez, a maioria das opiniões dos deputados do bloco PMDB/PTB/PP/PR aproxima-se mais do bloco PSDB/DEM/PPS do que do PT e seus aliados em grande parte das questões analisadas.

Levando em consideração métodos distintos, segundo Tarouco \& Madeira (2013), os partidos brasileiros têm sido classificados sem muitas controvérsias. A disposição de PT e PDT na esquerda, PMDB e PSDB no centro e PP, PTB, DEM, dentre outros, na direita, pode ser verificada em várias classificações adotadas. A classificação do PMDB e do PSDB demonstra o que há de mais controverso nessa discussão.

Embora o PSDB surja como uma ala à esquerda do PMDB, as coligações e as diretrizes das políticas adotadas colocam em cheque seu posicionamento no espectro político-ideológico. Em relação ao PMDB, 


\section{A INFLUÊNCIA DAS IDEOLOGIAS PARTIDÁRIAS NOS GASTOS PÚBLICOS EM ASSISTÊNCIA SOCIAL NAS CAPITAIS BRASILEIRAS}

para além do comportamento político, há demonstração nos manifestos partidários de que pretende e está guinando à direita, como mostra documento divulgado e outubro de 2015 pelo PMDB à nação e intitulado "Uma Ponte para o Futuro". Tal documento defende, dentre outras coisas, redução das despesas públicas e da carga tributária; sugere acabar com as vinculações constitucionais estabelecidas; aumento do superávit primário; e participação mais efetiva do setor privado. Coloca ainda a pertinência de um Estado mais enxuto para fazer frente à profunda recessão e severa crise fiscal (PMDB, 2015). Diante disso, para Scheeffer (2018a, 2018b) os partidos tradicionalmente considerados como centro (PMDB e PSDB) vêm demonstrando claros indícios das suas guinadas à direita, embora a ciência política venha de alguma forma "fechando os olhos" para tais evidências.

Scheeffer (2018b) aborda alguns métodos de classificação dos partidos brasileiros. Analisados de forma isolada, vê-se que esses partidos podem simplesmente se apresentar enquanto um cardápio de propostas bem-vindas para a maioria dos eleitores, sem condizer necessariamente com o comportamento de seus membros. Em relação aos surveys aplicados aos atores políticos, pode-se supor que aquele com uma mínima sofisticação política consiga decifrar facilmente o que o eleitor quer ler ou ouvir, sem necessariamente, como no caso anterior, agir de forma espelhada. Assim, analisar o comportamento efetivo é um dos métodos mais importantes para verificar o posiciona- mento dos partidos no espectro ideológico, visto que constata, afinal, aquilo que se demonstra mais relevante: a ação política.

\section{PROCEDIMENTOS METODOLÓGICOS}

O estudo em questão busca verificar os gastos públicos de todas as capitais brasileiras na área de assistência social, e não incluiu Brasília por não ser considerada um munícipio propriamente dito, já que não tem desde 1969.

Diante dos objetivos que o trabalho propõe, as informações contábeis foram retiradas do Sistema de Informações Contábeis e Fiscais do Setor Público Brasileiro (Siconfi), em que foram encontradas as receitas da corrente líquida, que significam o somatório das receitas tributárias de um governo, referente a contribuições patrimoniais, industriais, agropecuárias e de serviços, deduzidos os valores das transferências constitucionais. Também foram coletadas as despesas liquidadas com assistência social, ou seja, que já foram realizadas e existe um respectivo credor. Foram somados os gastos levando-se em consideração todas as subfunções como assistência social ao idoso, assistência ao portador de deficiência, assistência à criança e ao adolescente e assistência comunitária. Esses dados foram coletados nos anos de 2013 a 2016. Diante do que foi exposto até então, sobretudo a problematização apresentada no final do capítulo anterior, o quadro a seguir expõe a classificação dos partidos adotada nesse estudo. 
Quadro 2. Classificação E/D utilizada

\begin{tabular}{|c|c|}
\hline Esquerda & Direita \\
\hline PCdoB PDT PPS PSB PSOL PT PV & DEM PMDB PP PR PSD PSDB PTC \\
\hline
\end{tabular}

Fonte: Scheeffer (2018b).

Pelos motivos expostos na fundamentação teórica, esperaria-se que a esquerda investisse mais em assistência social e a direita menos. Com o intuito de cruzar os gastos Quadro 3. Critérios do enquadramento ideológico

\begin{tabular}{|l|l|}
\hline Esquerda (E-E) & $\begin{array}{l}\text { Quando o prefeito é considerado de es- } \\
\text { querda e o vice-prefeito é considerado de } \\
\text { esquerda. }\end{array}$ \\
\hline Esquerda - Direita (E-D) & $\begin{array}{l}\text { Quando o prefeito é considerado de esquer- } \\
\text { da e o vice-prefeito é considerado de direita. }\end{array}$ \\
\hline Direita - Esquerda (D-E) & $\begin{array}{l}\text { Quando o prefeito é considerado de direita e } \\
\text { o vice-prefeito é considerado de esquerda. }\end{array}$ \\
\hline Direita (D-E) & $\begin{array}{l}\text { Quando o prefeito é considerado de direita e } \\
\text { o vice-prefeito é considerado de direita. }\end{array}$ \\
\hline
\end{tabular}

Fonte: Adaptado de Rodrigues (2010).
Para concorrer com a variável ideologia, foram inseridos no modelo o Índice de Desenvolvimento Humano Municipal (IDHM). Realizado com base em três dimensões (saúde, educação e a renda), o índice registra dados que são coletados de dez em dez anos. Por isso foram utilizados os dados de 2010. De acordo com Prearo, Maraccini, \& Romeiro (2015), o índice tem como objetivo calcular os requisitos mais importantes para uma públicos com as ideologias políticas, foram criadas categorias de análise, o que foi chamado de enquadramento ideológico como é apresentado na sequência. o vice-prefeito é considerado de direita.

vida que seja considerada saudável, como saúde (longevidade), educação (escolaridade) e renda (per capita).

A Tabela 1 apresenta os munícipios que estão presentes no estudo, IDHM, partidos que estão no comando das prefeituras entre os anos de 2013 e 2016, assim como o enquadramento ideológico exposto acima. 
Tabela 1. Capitais brasileiras, IDHM e enquadramento ideológico

\begin{tabular}{lllll}
\hline Capital & 2010 & & \multicolumn{2}{c}{2013 a 2016} \\
& IDHM & Prefeito & Vice-prefeito & Enquadramento \\
\hline Aracaju & 0,770 & DEM & PSDB & Direita (D-D) \\
Belém & 0,746 & PSDB & PSB & Direita-Esquerda (D-E) \\
Belo Horizonte & 0,810 & PSB & PV & Esquerda (E-E) \\
Boa Vista & 0,752 & PMDB & PSDB & Direita (D-D) \\
Campo Grande & 0,784 & PP & PP & Direita (D-D) \\
Cuiabá & 0,785 & PSB & PR & Esquerda-Direita (E-D) \\
Curitiba & 0,823 & PDT & PT & Esquerda (E-E) \\
Florianópolis & 0,847 & PSD & PP & Direita (D-D) \\
Fortaleza & 0,754 & PSB & PMDB & Esquerda-Direita (E-D) \\
Goiânia & 0,799 & PT & PMDB & Esquerda-Direita (E-D) \\
João Pessoa & 0,763 & PT & PPS & Esquerda (E-E) \\
Macapá & 0,736 & PSOL & PPS & Esquerda (E-E) \\
Maceió & 0,721 & PSDB & PP & Direita (D-D) \\
Manaus & 0,737 & PSDB & PPS & Direita-Esquerda (D-E) \\
Natal & 0,763 & PDT & PSB & Esquerda (E-E) \\
Palmas & 0,788 & PP & PPS & Direita-Esquerda (D-E) \\
Porto Alegre & 0,805 & PDT & PMDB & Esquerda-Direita (E-D) \\
Porto Velho & 0,736 & PSB & PDT & Esquerda (E-E) \\
Recife & 0,772 & PSB & PCdoB & Esquerda (E-E) \\
Rio Branco & 0,727 & PT & PCdoB & Esquerda (E-E) \\
Rio de Janeiro & 0,799 & PMDB & PT & Direita-Esquerda (D-E) \\
Salvador & 0,759 & DEM & PV & Direita-Esquerda (D-E) \\
São Luís & 0,768 & PTC & PSB & Direita-Esquerda (D-E) \\
São Paulo & 0,805 & PT & PCdoB & Esquerda (E-E) \\
Teresina & 0,751 & PSDB & PSD & Direita (D-D) \\
Vitória & 0,845 & PPS & PR & Esquerda-Direita (E-D) \\
\hline
\end{tabular}

Com a intenção de verificar a dispersão e a variabilidade dos gastos nos quatro anos do mandato, foi utilizado o coeficiente de variação (CV), calculado pelo desvio padrão dividido pela média X 100 (Crespo, 2009). Segundo o autor, o desvio padrão por si só não nos diz muita coisa. Para Fonseca \& Martins
(2015), tem-se baixa dispersão quando CV $\leq 15 \%$, média dispersão CV > 15\% < 30\% e alta dispersão $\mathrm{CV} \geq 30 \%$. Como na maioria dos casos a variação foi baixa, foi utilizada a média dos gastos nos quatro anos. A tabela 2 demostra o resultado do cálculo de variação. 
Tabela 2. Cálculo do coeficiente de variação

\begin{tabular}{lllllllll}
\hline Capitais & 2013 & 2014 & 2015 & 2016 & Média & Desvio Padrão & $\begin{array}{l}\text { Coef. } \\
\text { Var (\%) }\end{array}$ & Interpretação \\
\hline Aracaju & 2,26 & 2,4 & 2,64 & 2,64 & 2,49 & 0,187882942 & 7,56 & fraca \\
Belém & 2,72 & 2,87 & 2,99 & 2,63 & 2,80 & 0,159452187 & 5,69 & fraca \\
Belo Horizonte & 2,76 & 2,89 & 2,54 & 2,34 & 2,63 & 0,242676053 & 9,22 & fraca \\
Boa Vista & 2,03 & 3,83 & 0 & 3,72 & 2,40 & 1,796672851 & 75,02 & forte \\
Campo Gran- & 1,27 & 1,55 & 1,72 & 1,89 & 1,61 & 0,264370321 & 16,45 & moderada \\
de & & & & & & & & \\
Cuiabá & 2,73 & 3,13 & 2,68 & 2,38 & 2,73 & 0,3082207 & 11,29 & fraca \\
Curitiba & 2,07 & 2,38 & 2,16 & 2,29 & 2,23 & 0,137234592 & 6,17 & fraca \\
Florianópolis & 3,16 & 3,71 & 3,72 & 5,57 & 4,04 & 1,053027382 & 26,07 & moderada \\
Fortaleza & 2,04 & 1,54 & 1,69 & 1,54 & 1,70 & 0,235849528 & 13,85 & fraca \\
Goiânia & 0,56 & 1,3 & 1,3 & 1,15 & 1,08 & 0,352171833 & 32,68 & forte \\
João Pessoa & 1,81 & 1,01 & 0,88 & 1,66 & 1,34 & 0,463249393 & 34,57 & forte \\
Macapá & 1,34 & 1,36 & 1,57 & 1,48 & 1,44 & 0,107819293 & 7,50 & fraca \\
Maceio & 0,99 & 0,9 & 1,19 & 1,4 & 1,12 & 0,222560853 & 19,87 & moderada \\
Manaus & 2,84 & 2,8 & 2,66 & 2,44 & 2,69 & 0,180646985 & 6,73 & fraca \\
Natal & 1,92 & 0,42 & 2,85 & 2,55 & 1,94 & 1,081804049 & 55,91 & forte \\
Palmas & 2,68 & 2,75 & 2,23 & 2,49 & 2,54 & 0,232576152 & 9,17 & fraca \\
Porto Alegre & 3,87 & 3,81 & 3,96 & 3,95 & 3,90 & 0,070887234 & 1,82 & fraca \\
Porto Velho & 2,22 & 2,24 & 2,48 & 1,82 & 2,19 & 0,273495887 & 12,49 & fraca \\
Recife & 0,94 & 1,25 & 1,68 & 1,54 & 1,35 & 0,328164085 & 24,26 & moderada \\
Rio Branco & 3,13 & 1,7 & 2,2 & 2,48 & 2,38 & 0,596454804 & 25,09 & moderada \\
Rio de Janeiro & 3,29 & 3,56 & 3,34 & 3,19 & 3,35 & 0,156311655 & 4,67 & fraca \\
Salvador & 1,08 & 1,71 & 2,05 & 2,53 & 1,84 & 0,609555849 & 33,08 & forte \\
São Luís & 1,61 & 1,88 & 1,61 & 1,66 & 1,69 & 0,128840987 & 7,62 & fraca \\
São Paulo & 2,73 & 2,24 & 2,41 & 2,72 & 2,53 & 0,241177666 & 9,55 & fraca \\
Teresina & 1,94 & 2,34 & 2,25 & 2,01 & 2,14 & 0,190525589 & 8,92 & fraca \\
Vitória & 6,09 & 4,92 & 6,76 & 6,19 & 5,99 & 0,771967184 & 12,89 & fraca \\
\hline & & & & & & & &
\end{tabular}

Segundo Fávero \& Belfiore (2017), a estatística descritiva busca descrever esintetizar elementos principais observados em um conjunto de dados por meio de recursos como tabelas, gráficos ou medidas-resumo. Uma primeira técnica utilizada foi o uso de box-plot, também chamado de "diagrama de caixa." Segundo os autores, trata-se de uma representação gráfica com cinco medidas de posição ou localização de determinada variável, sendo elas de baixo para cima: valor mínimo; primeiro quartil; segundo quartil ou mediana; terceiro quartil; e valor máximo. 0 primeiro quartil descreve $25 \%$ dos primeiros 
dados. O terceiro quartil corresponde a $75 \%$ das observações. O valor mínimo e máximo excetuando os outliers. A mediana por sua vez é o valor que separa a metade maior e a menor de uma amostra. A utilização do gráfico permite avaliar a simetria e distribuição dos dados.

Verificada a distribuição dos dados, foi feito um teste de correlação e nessecaso foi calculado o coeficiente de correlação de Spearman. Trata-se de uma medida de intensidade da correlação entre duas variáveis que podem ser mensuradas de forma ordinal (existe uma ordenação entre as categorias). O coeficiente mede a força e a direção da relação (Martins \& Rodrigues, 2011).

Por último, foi realizada uma análise multivariada, a regressão linear múltipla. Para Fávero \& Belfiore (2017), o modelo linear de regressão permite a possibilidade de que seja estudada a relação entre uma ou mais variáveis explicativas que se apresentam de forma linear e uma variável dependente quantitativa. De forma geral, o objetivo da análise de regressão é prever os valores de uma única variável dependente a partir do conhecimento de uma ou mais variáveis independentes. Quando há o envolvimento de duas ou mais variáveis independentes, estamos falando de uma regressão múltipla.

\section{ANÁLISE E DISCUSSÃO DOS RESULTA- DOS}

Primeiramente utilizou-se a análise box-plot, também conhecida como "diagrama de caixa", que permite identificar a simetria e distribuição dos dados, ou seja, comparar os gastos entre os diferentes enquadramentos ideológicos.

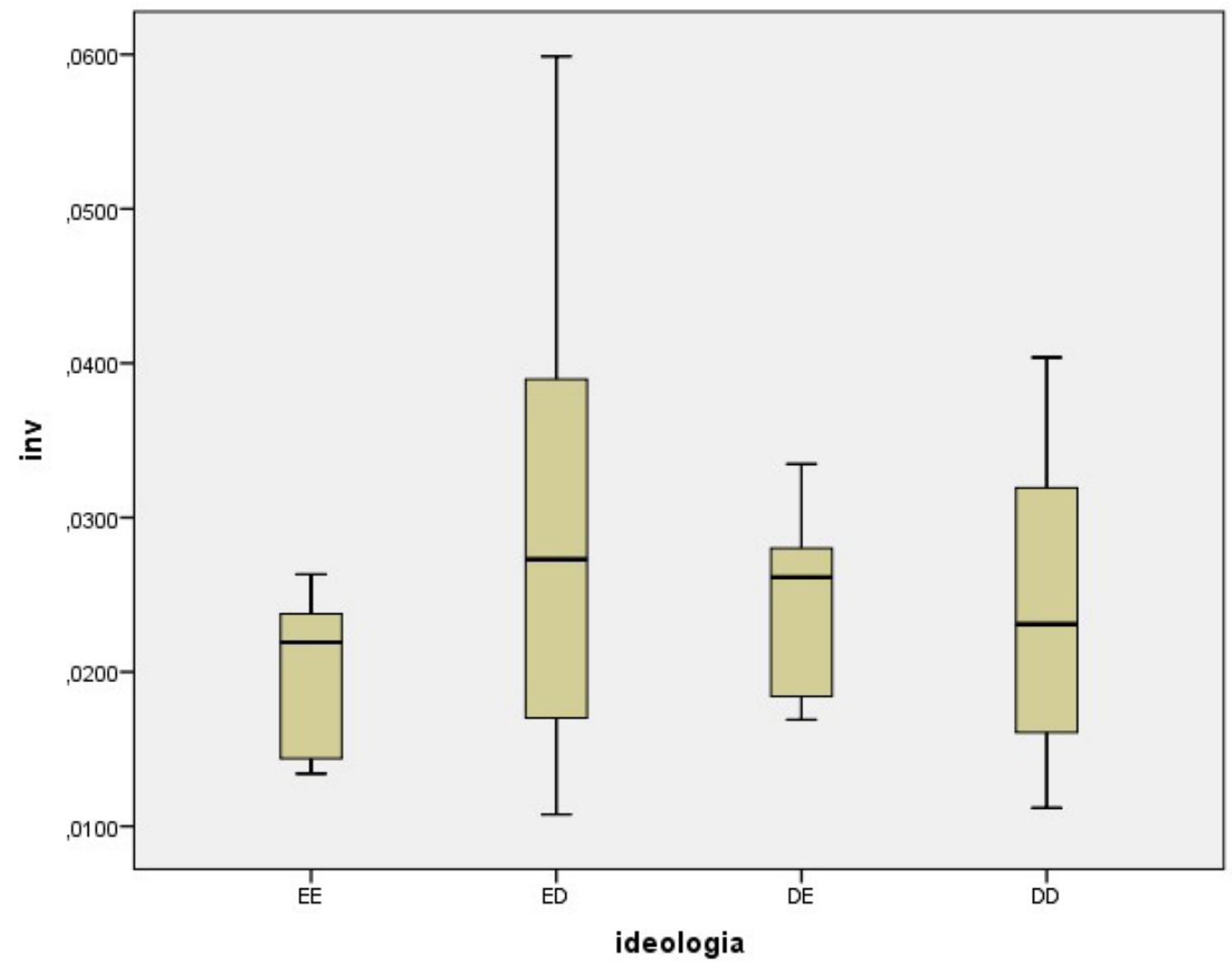


Diferentemente do que se imaginava, os partidos de Esquerda (E-E) tendem a gastar menos em comparação aos demais partidos. As categorias Esquerda-Direita (E-D) e Direita-Esquerda (D-E) são as que apresentam maiores gastos em assistência social. $\mathrm{O}$ que se percebe aqui também é que a maior variabilidade de dados ocorre na categoria Esquerda-Direita (E-D). De forma geral percebe- se que não há uma relação entre enquadramento ideológico e gastos públicos, semelhante ao que é constatado por Rodrigues (2010).

O autor fez uma análise quantitativa dos investimentos realizados nos maiores municípios catarinenses durante uma gestão governamental (2005-2008) a fim de testar a tese de que haveria diferenças entre os partidos políticos com matrizes teóricas distintas e que estas impactaram nos investimentos públicos. Não há um padrão de gasto diferente entre os partidos de diversas localizações no espectro ideológico. No que diz respeito à assistência social, o autor detectou haver uma dissonância no último ano do mandato, gastando-se bem mais do que nos anos anteriores.
Uma das possíveis explicações para a esquerda não ser a categoria que mais investe em assistência social pode estar no que é apontado por Arvate, Avelino Filho, \& Lucinda (2008). Buscando verificar se a ideologia partidária teria influência sobre gastos públicos entre os governos estaduais do Brasil, os autores concluíram que partidos considerados de esquerda consideram aumentar seus gastos públicos com relação ao PIB estadual, e surpreendentemente os partidos considerados de direita tendem a dar mais prioridade aos gastos sociais do que os demais partidos. Para eles, ao contrário do que se espera, a direita tende a priorizar mais os gastos sociais do que a esquerda. Uma das possíveis explicações seria a tentativa de seduzir politicamente o eleitor de esquerda.

Outra análise realizada foi a verificação da correlação utilizando-se mais especificamente o método de Spearman. A tabela 3, além de tentar encontrar uma correlação entre ideologia política e gastos públicos com assistência social, ainda permite verificar se há uma relação entre gasto público com IDHM.

Tabela 3. Correlação de Spearman

\begin{tabular}{|c|c|c|c|c|c|}
\hline & & & inv & ideologia & idh \\
\hline \multirow{9}{*}{ Spearman's rho } & \multirow[b]{3}{*}{$\operatorname{lnv}$} & Correlation Coefficient & 1,000 & , 190 &, $406^{*}$ \\
\hline & & Sig. (2-tailed) & . & ,352 & ,040 \\
\hline & & $\mathrm{N}$ & 26 & 26 & 26 \\
\hline & \multirow[b]{3}{*}{ Ideologia } & Correlation Coefficient & ,190 & 1,000 &,- 081 \\
\hline & & Sig. (2-tailed) & ,352 & . & ,695 \\
\hline & & $\mathrm{N}$ & 26 & 26 & 26 \\
\hline & \multirow[b]{3}{*}{ Idhm } & Correlation Coefficient &, $406^{*}$ &,- 081 & 1,000 \\
\hline & & Sig. (2-tailed) &, 040 & ,695 & . \\
\hline & & $\mathrm{N}$ & 26 & 26 & 26 \\
\hline
\end{tabular}

*. Correlation is significant at the 0.05 level (2-tailed). 


\section{A INFLUÊNCIA DAS IDEOLOGIAS PARTIDÁRIAS NOS GASTOS PÚBLICOS EM ASSISTÊNCIA SOCIAL NAS CAPITAIS BRASILEIRAS}

Como se pode notar, apenas a variável IDHM se demonstrou significativa (Sig. $(2$-tailed) $<0,05)$. Há entre investimentos (inv) e IDHM uma correlação positiva $(, 406)$. Isso permite inferir que um aumento no IDHM implica um aumento no investimento.

O resultado é aparentemente contraintuitivo, levando em consideração que se esperaria que, quanto menor o IDHM, maior deveria ser o gasto com assistência social, justamente para alavancar o índice. Em contrapartida, faz sentido supor que uma cidade que investe mais em assistência social tende a ter melhores índices, isto é, fica difícil estabelecer uma relação precisa de causa e efeito. É o que se constata em Scarpin, Pinto, \& Silva (2007). Os autores corroboram que as receitas públicas têm influência positiva com o IDHM e que, quanto maior o gasto público, maior o IDHM. Na contramão, Prearo, Maraccini, \& Romeiro (2015) afirmam que os gastos em assistência so- cial são mais vultosos quando o IDHM é de até 0,718 . Quando esse índice é acima de 0,761 até 1,000 , os municípios tendem a investir até $28,9 \%$ menos em assistência social que os demais. Segundo os autores, isso acontece porque as cidades com menor índice no desenvolvimento humano tendem a preocupar-se mais com os gastos sociais. A análise foi feita nos municípios do Estado de São Paulo.

Na última análise, foi utilizada a regressão linear múltipla que permite verificar a relação entre as duas variáveis independentes (IDH e ideologia política) com a variável dependente investimento. Para efetuar a regressão, foram inseridas variáveis dummy (numéricas) para representar as variáveis qualitativas relacionadas à ideologia (EE, $E D, D E$ e DD). A regressão linear múltipla utilizando a variável investimentos (inv) como dependente da ideologia e IDHM resultou no modelo abaixo.

Tabela 4. Resumo do modelo 1

\begin{tabular}{|l|l|l|l|l|l|}
\hline Model & R & R Square & $\begin{array}{l}\text { Adjusted R } \\
\text { Square }\end{array}$ & $\begin{array}{l}\text { Std. Error of the } \\
\text { Estimate }\end{array}$ & Durbin-Watson \\
\hline 1 &, $633^{a}$ &, 401 &, 287 &, 0090305 & 1,918 \\
\hline
\end{tabular}

a. Predictors: (Constant), idh, d3, d2, d1

b. Dependent Variable: inv

De acordo com Hair Jr., J. F., Black, W. C., Babin, B. J., Anderson, R. E., \& Tatham, R. L. (2009), o coeficiente $R^{2}$ mensura a explicação da variável dependente. Ou seja, quanto maior o valor de $\mathrm{R}^{2}$, maior o poder de explicação da equação de regressão utilizada. A partir da tabela em questão, é possível verificar que o conjunto de variáveis explica $28,7 \%$ da variação dos investimentos.
Também se nota que não há problemas de multicolinearidade dos resíduos já que a estatística de Durbin-Watson é próxima a 2. Pela tabela ANOVA (tabela 5) apresentada a seguir é possível verificarmos que o modelo proposto apresenta significância estatística, ou seja, pelo menos uma das variáveis explicativas incluídas é significante para explicar os investimentos. 
Tabela 5. Significância do modelo 1 - ANOVA

\begin{tabular}{|c|c|c|c|c|c|}
\hline Model & Sum of Squares & Df & Mean Square & $\mathrm{F}$ & Sig. \\
\hline Regression & ,001 & 4 & ,000 & $\begin{array}{c}3,5 \\
12\end{array}$ &, $024^{b}$ \\
\hline Residual & ,002 & 21 & ,000 & & \\
\hline Total & ,003 & 25 & & & \\
\hline
\end{tabular}

a. Dependent Variable: inv

b. Predictors: (Constant), idh, d3, d2, d1

Feito isso, parte-se para a análise estatística dos parâmetros de cada variável explicativa. Os resultados encontram-se na tabela 6 .

Tabela 6. Significância dos parâmetros da regressão múltipla - Modelo 1

\begin{tabular}{|c|c|c|c|c|c|c|c|c|c|c|c|c|}
\hline \multirow[t]{2}{*}{ Model } & & \multicolumn{3}{|c|}{$\begin{array}{l}\text { Unstandardized Coeffi- } \\
\text { cients }\end{array}$} & \multirow[t]{2}{*}{$\begin{array}{l}\text { Standardi- } \\
\text { zed Coeffi- } \\
\text { cients }\end{array}$} & \multicolumn{2}{|c|}{$\begin{array}{l}\mathrm{T} \\
\text { Tolerance }\end{array}$} & \multirow{2}{*}{\multicolumn{2}{|c|}{$\begin{array}{l}\text { Sig. } \\
\text { IF } \\
\text { V }\end{array}$}} & \multicolumn{3}{|c|}{ Collinearity Statistics } \\
\hline & \multicolumn{2}{|l|}{ B } & \multirow{3}{*}{$\begin{array}{l}\text { Std. } \\
\text { Error } \\
-\end{array}$} & \multirow{3}{*}{$\begin{array}{l}\text { Beta } \\
, 043\end{array}$} & & & & & & & & \\
\hline & \multirow[t]{2}{*}{ Constant } & & & & & & - & & ,01 & & & \\
\hline & & ,112 & & & & 2,598 & & 7 & & & & \\
\hline & \multirow[t]{2}{*}{ d1 } & & , & \multirow[t]{2}{*}{,005 } & \multirow[t]{2}{*}{,231 } & & 1,1 & & ,25 & \multirow[t]{2}{*}{,731 } & & \multirow[t]{2}{*}{1} \\
\hline & & 006 & & & & 69 & & 6 & & & ,369 & \\
\hline & \multirow[t]{2}{*}{ d2 } & & , & \multirow[t]{2}{*}{,005 } & \multirow[t]{2}{*}{,224 } & & 1,1 & & ,25 & \multirow[t]{2}{*}{,778 } & & 1 \\
\hline & & 006 & & & & 70 & & 5 & & & ,285 & \\
\hline & \multirow[t]{2}{*}{ d3 } & & , & \multirow[t]{2}{*}{,005 } & \multirow[t]{2}{*}{, 170 } & & ,89 & & ,38 & \multirow[t]{2}{*}{,780 } & & 1 \\
\hline & & 004 & & & & 0 & & 4 & & & ,282 & \\
\hline & \multirow[t]{2}{*}{ Idh } & & , & \multirow[t]{2}{*}{,056 } & \multirow[t]{2}{*}{, 550} & & 3,0 & & ,00 & \multirow[t]{2}{*}{,889 } & & 1 \\
\hline & & 171 & & & & 71 & & 6 & & & ,125 & \\
\hline
\end{tabular}

Observa-se que apenas a variável IDH explica a variável dependente investimentos (Sig.<0,05), ou seja, nesta amostra, ideologia não interfere nos gastos com investi- mentos. Assim, uma nova regressão foi gerada, considerando somente a variável IDH como explicativa.

Tabela 7. Resumo do modelo 2

\begin{tabular}{|l|l|l|l|l|l|}
\hline Model & $R$ & R Square $^{\mathrm{b}}$ & $\begin{array}{l}\text { Adjusted R } \\
\text { Square }\end{array}$ & $\begin{array}{l}\text { Std. Error of } \\
\text { the Estimate }\end{array}$ & Durbin-Watson \\
\hline 1 &, $927^{\mathrm{a}}$ &, 859 &, 853 &, 0101001 & 1,711 \\
\hline
\end{tabular}




\section{A INFLUÊNCIA DAS IDEOLOGIAS PARTIDÁRIAS NOS GASTOS PÚBLICOS EM ASSISTÊNCIA SOCIAL NAS CAPITAIS BRASILEIRAS}

Esse modelo final consegue explicar em torno de $85,3 \%$ ( $R$ ajustado) as variações dos investimentos por meio das variações do IDHM. Essas interpretações podem ser feitas porque a regressão linear obedeceu aos pressupostos necessários para a aplicação da regressão: ausência de autocorrelação serial (independência dos erros) - teste de Durbin-Watson.

Tabela 8. Significância dos parâmetros da regressão múltipla - Modelo 2

\begin{tabular}{|c|c|c|c|c|c|c|c|c|}
\hline \multirow[t]{2}{*}{ Model } & \multirow{2}{*}{$B$} & \multicolumn{2}{|c|}{$\begin{array}{c}\text { Unstandardized } \\
\text { Coefficients }\end{array}$} & \multirow[t]{2}{*}{$\begin{array}{l}\text { Standardized } \\
\text { Coefficients }\end{array}$} & & \multirow{2}{*}{$\begin{array}{c}\text { ig. } \\
\text { Tolerance }\end{array}$} & \multicolumn{2}{|c|}{ Collinearity Statistics } \\
\hline & & $\begin{array}{l}\text { Std. } \\
\text { Error }\end{array}$ & Beta & & & & VIF & \\
\hline 1 & idhm & ,032 & ,003 & ,927 & 2,334 & 000 & 1,000 & 1,000 \\
\hline
\end{tabular}

Por meio desse novo modelo, fica evidente a relação entre IDHM e investimentos em assistência social nas capitais brasileiras no período de 2013 a 2016. O resultado da regressão permite inferir que a relação entre investimentos e IDHM é positiva $(+0,032)$.

Em outras palavras, mesmo tendo ciência do problema temporal (IDHM 2010, gastos 2013-2016), pode-se inferir que a variação de 1 ponto percentual em IDHM provoca uma variação positiva de 0,032 pontos percentuais no investimento (arrecadação/ despesa). A pesquisa de Mattei, Bezerra, \& Mello (2017) reafirma as considerações do estudo em questão. Segundo eles, a cada $1 \%$ de aumento nas despesas per capita destinadas à saúde, assistência e previdência, acrescentam-se 0,047 pontos no nível do IDHM. Ainda para os autores, não é inusitado que despesas em áreas- chave impactam positivamente no nível de desenvolvimento. Com isso percebe- se o papel importante do governo para promover meIhor qualidade de vida das pessoas por meio do direcionamento apropriado de recursos.

\section{CONSIDERAÇÕES FINAIS}

O estudo em questão teve como objetivo geral analisar a influência ou o impacto que a ideologia política teve sobre os gastos com assistência social nos anos de 2013 a 2016. Outro ponto analisado de forma complementar foi a possível relação entre investimentos na área e o IDHM de cada capital brasileira. Se do ponto de vista teórico é possível afirmar que na social-democracia o conceito de direitos sociais é central, no neoliberalismo o insucesso é resultado sobretudo da falta de esforço e mérito. Essas distinções em boa parte denotam diferenças significativas entre o ideário de esquerda e direita em tempos atuais.

A partir das análises realizadas, diferentemente do esperado, a esquerda não tende a gastar mais em assistência social. Embora de um ponto de vista teórico se esperasse que em nome da igualdade social a assistência social devesse ser uma área prioritária, o que se verificou foi que não há uma relação significativa entre ideologia e inves- 
timentos. Há uma certa homogeneidade de gastos por parte dos diferentes enquadramentos ideológicos.

Um dos prováveis motivos para que isso ocorra é a influência do Plano Plurianual (PPA), plano orçamentário de médio prazo. Por mais que o Executivo encaminhe, os PPAs são aprovados pelo Legislativo municipal. Os vereadores decidem se pode ser aprovado, negado ou se serão realizadas modificações. A problemática central da pesquisa é o impacto da ideologia política nos gastos públicos com assistência social e o que foi constatado de forma clara e objetiva foi a independência entre esses dois fatores. Não há um padrão de gastos diferenciado entre partidos de esquerda ou direita, corroborando com o que é constatado por Rodrigues (2010). Talvez as variações sejam qualitativas, mas não quantitativas. Essa homogeneidade possivelmente se deva a fatores estruturantes muito mais do que a uma razão conjuntural. Ou seja, haveria uma certa "amarração" orçamentária que daria um menor grau de autonomia aos agentes políticos em nível municipal.

Dito de outra forma, é possível que em outros níveis federativos sejam percebidas diferenças significativas dado o maior grau de autonomia. $\mathrm{O}$ que apresentou uma surpresa no estudo foi a relação entre o IDHM e investimento. Quanto maior o IDHM, maior o investimento.

Embora Scheeffer (2018) tenha em seu estudo percebido diferenças significativas entre parlamentares de esquerda e direita na Câmara dos Deputados (sabendo se o parlamentar/partido é de esquerda ou de direita é possível prever razoavelmente a atuação em plenário), as exceções são os casos em que estão envolvidos recursos financeiros vultosos. Nesses casos, o posicionamento estratégico (pertencimento ao governo ou à oposição) teria melhor poder explicativo. Esse argumento pode auxiliar a compreender as pequenas diferenças no Executivo municipal. Em se tratando de assistência social, uma área sensível do ponto de vista político-ideológico, talvez fosse sensato supor que não haveria distinções de gastos públicos emnível municipal de gestões de partidos localizados em espectros ideológicos diferentes.

Para além de análises qualitativas (tipo de políticas adotadas), fica como recomendação a comparação de séries temporais mais extensas cobrindo mais de um mandato, bem como a análise por subfunção e não só dos gastos gerais da política pública em questão.

\section{REFERÊNCIAS}

Aggio, A. (2013). Construir uma esquerda transformadora. In Almeida, F. I. de. (org.). O que é ser esquerda hoje? Rio de Janeiro: Contraponto.

Anderson, P. (1995). Balanço do Neoliberalismo. In Sader, E.; Borón, A. (Orgs.). Pós-neoliberalismo: As políticas sociais e o Estado democrático. 3. ed. Rio de Janeiro: Paz e Terra.

Arvate P. R., Avelino Filho, G., \& Lucinda, C. R. (2008). Ideologia partidária e gastos públicos entre os governos estaduais no Brasil. Encontro de Administração Pública e Governança, 38(4)789-814.

Bobbio, N. (1995). Direita e esquerda: Ra- 


\section{A INFLUÊNCIA DAS IDEOLOGIAS PARTIDÁRIAS NOS GASTOS PÚBLICOS EM ASSISTÊNCIA SOCIAL NAS CAPITAIS BRASILEIRAS}

zões e significados de uma distinção política. São Paulo: Editora da UNESP.

Budge, I., Klingemann, H-D., Volkens, A., Bara, J., \& Tanenbaum, E. (2001). Mapping policy preferences: estimates for parties, electors and governments - 1945-1998. New York: Oxford University Press.

Carvalho, G. F. (2008). A assistência social no Brasil: Da caridade ao direito. 56f. TrabaIho de Conclusão de Curso (Bacharelado) - Faculdade de Direito, Pontifícia Universidade Católica do Rio de Janeiro, Rio de Janeiro.

Crespo, A. A. (2009). Estatística fácil. 19. ed. São Paulo: Saraiva.

Dalton, R, J., \& McAllister, I. (2014). Random walk or planned excursion? Continuity and change in the left-right positions of political parties. Comparative Political Studies. December 9.

Fávero, L. P., \& Belfiore, P. (2017). Manual de análise de dados: Estatística e modelagem multivariada com Excel, SPSS e Stata. Rio de Janeiro: Elsevier.

Garcia, A. V. (2005). A pobreza do homem. Florianópolis. 364 f. (Tese de Doutorado). Recuperado de https://repositorio.ufsc.br/ handle/123456789/101897.

Giddens. A. (2000). A terceira via: reflexões sobre o impasse político atual e o futuro da social-democracia. Rio de Janeiro: Record.

Hair Jr., J. F., Black, W. C., Babin, B. J., Anderson, R. E., \& Tatham, R. L. (2009). Análise multivariada de dados. 6. ed. Porto Ale- gre: Bookman.

Heywood, A. (2010). Ideologias políticas: do liberalismo ao fascismo. São Paulo: Ática.

Inglehart, R. (1977). The silent revolution. Princeton: Princeton University Press.

Jaccoud, L., Bichir, R., \& Mesquita, A. C. (2017). O SUAS na proteção social brasileira: Transformações recentes e perspectivas. Novos estudos CEBRAP, 36(2)3753. Recuperado de http://novosestudos.uol. com.br/wp- content/uploads/2017/09/03_ jaccoud_dossie_108_p36a53_site.pdf

KINZO, M. D. (1993). Radiografia do quadro partidário brasileiro. São Paulo: Fundação Konrad-Adenauer-Stiftung.

Klingemann, H-D., Volkens, A., Bara, J., Tanenbaum, E., \& McDonald, M. (2006). Mapping policy preferences II: estimates for parties, electors and governments in Central and Eastern Europe, European Union and OECD - 1990-2003. New York: Oxford University Press.

Leoni, E. (2002). Ideologia, democracia e comportamento parlamentar: A câmara dos deputados (1991-1998). DADOS, Rio de Janeiro, 45(3)361-386.

Lucas, K., \& Samuels, D. (2011). A "coerência" ideológica do sistema partidário brasileiro, 1990-2009. In Power, T. J.; Zucco Jr. (orgs). O congresso por ele mesmo: Autopercepções da classe política brasileira. Belo Horizonte: Editora UFMG.

Mainwaring, S. P. (1993). Democracia presidencialista multipartidária: o caso do Bra- 
sil. Lua Nova: Revista de Cultura Política, (28-29), 21-74. Recuperado de: http://www. scielo.br/scielo.php?script=sci_arttext\&pid =S0102-64451993000100003

Martins, G. de A., \& Rodrigues, O. (2011). Estatística geral e aplicada. 4. ed. São Paulo: Atlas.

Melo, C. R., \& Câmara, R. (2012). Estrutura da competição pela presidência e consolidação do sistema partidário no Brasil. Dados, Revista de Ciências Sociais, Rio de Janeiro, 55(1)71-117.

Mattei, T. F., Bezerra, F. M., \& Mello, G. R. (2018). Despesas públicas e o nível de desenvolvimento humano dos estados brasileiros: Uma Análise do IDHM 2000 e 2010. RACE: Revista de Administração, Contabilidade e Economia, 17 (1)29-54.

Moraes, R. C. (2002). Reformas neoliberais e políticas públicas: Hegemonia ideológica e redefinição das relações Estado-sociedade. Educação \& Sociedade, 23(80)13-24. Recuperado de http:// www.scielo.br/scielo.php? pid=S0101$73302002008000002 \&$ script $=s c i$ abstract\&tlng=pt

\section{PMDB. (2015). Uma ponte} para $o$ futuro. 29 out. Recuperado de

<http://pmdb.org.br/wp-content/uploads/2015/10/RELEASE-TEMER_A428.10.15-Online.pdf>

Prearo, L. M., Maraccini, M. C., \& Romeiro M. C. (2015). Fatores determinantes do índice de desenvolvimento humano dos municípios do estado de São Paulo. Revista
Brasileira de Políticas Públicas, Brasília, 5(1)132-155.

Rodrigues, G. (2010). Partidos políticos e gastos públicos em Santa Catarina: A influência das ideologias partidárias nas decisões de investimentos. $263 \mathrm{f}$. (Tese de Pós-Graduação). Recuperado de https://repositorio.ufsc.br/xmlui/bitstream/handle/123456789/93997/281205. pdf? sequence $=1$ \&isAllowed $=y$

Roma, C. (2006). Agenda, ideologia e coesão partidária na Câmara dos Deputados. In: XXX Encontro anual da ANPOCS.

Santana, E. P., Silva, J. A. S., \& Silva, V. S. (2013). Histórico da política de assistência social: Uma construção lenta e desafiante, do âmbito das benesses ao campo dos direitos sociais. VI Jornada Internacional de Políticas Públicas.

Scarpin, J. E., Pinto, J., \& Silva A. J. (2007). Estudo dos fatores condicionantes do Índice de Desenvolvimento Humano nos municípios da região sul do Brasil: instrumento de definição de políticas públicas. Encontro da ANPAD, 2007, Rio de Janeiro. ENANPAD. Encontro da Anpad. Rio de Janeiro/RJ: ANPAD31. 1-15.

Setembrini, D. (1997). Social-Democracia. In: Bobbio, N.; Matteuci, N.; Pasquino, G. Dicionário de Política. Brasília: Universidade de Brasília, 9. ed.

Scheeffer, F. (2013). Pobreza: Um conceito controverso. CSOnline - Revista Eletrônica de Ciências Sociais, 7(16)131-148.

Scheeffer, F. (2018a). Esquerda e direita hoje: 


\section{A INFLUÊNCIA DAS IDEOLOGIAS PARTIDÁRIAS NOS GASTOS PÚBLICOS EM ASSISTÊNCIA SOCIAL NAS CAPITAIS BRASILEIRAS}

Uma análise das votações na Câmara dos Deputados. Curitiba: Appris.

Scheeffer, F. (2018b). A alocação dos partidos no espectro ideológico a partir da atuação parlamentar. E-legis. Brasília, (27)119-142. Recuperado de file:///C:/Users/3561208/ Downloads/435-2169-1-PB\%20.pdf

Souza, J. (2009). A ralé brasileira: Quem ée como vive. Belo Horizonte: Ed. UFMG.

Tarouco, G. S., \& Madeira, R. M. (2013). Partidos, programas e o debate sobre esquerda e direita no Brasil. Revista de Sociologia e
Política, 21(45)149- 165.

Zucco JR., C. (2009). Ideology or what? Legislative behavior in multiparty presidential settings. The Journal of Politics, 711.0761.092 .

Zucco JR., C. (2011). Esquerda, direita e governo: A ideologia dos partidos políticos brasileiros. In Power, T. J.; Zucco JR. (orgs). O congresso por ele mesmo: autopercepções da classe política brasileira. Belo Horizonte: Editora UFMG 